\title{
Die wirtschaftliche Situation in Ungarn Deutsch-Ungarische Wirtschaftsbeziehungen
}

\author{
Ferenc Takacs
}

Auch 1996 und im ersten Drittel von 1997 setzte sich die positive wirtschaftliche Entwicklung in Ungarn fort. Ausdruck des Fortschrittes der wirtschaftlichen Umgestaltung war insbesondere der Beitritt Ungarns zur OECD im März 1996. Die Aufnahme in die Vereinigung industriell entwickelter Länder erhöht das Vertrauen der Anleger und steigert die Attraktivität als Investitionsstandort. Am 30. Juni 1997 wurde in Paris die vierte Wirtschaftsstudie der OECD über Ungarn veröffentlicht. Dies ist die erste Prüfung Ungarns als Mitgliedsland. Der Rückgang des verfügbaren Realeinkommens aufgrund der im Stabilisierungsprogramm verordneten Lohndämpfung prägte 1995 und 1996 die inländische Wirtschaftsentwicklung.

So fiel der Verbrauch der privaten Haushalte um über $10 \%$ und die flaue Binnenmarktentwicklung zog einen drastischen Rückgang der Investitionen nach sich. Die sinkende Inlandsnachfrage führte aber nicht zu einem effektiven Rückgang des BIP-Wachstums, was den sehr günstigen Nettoexportergebnissen zu verdanken war. Die Exportwirtschaft nutzte die stärkere Wettbewerbsfähigkeit dazu, die Auslandsumsätze in den vergangenen zwei Jahren um über $20 \%$ zu steigern.

Dank des Rüickganges des Staatsdefizits und der inländischen Güternachfrage wiesen die Handelsbilanz wie auch die Leistungsbilanz eine spektakuläre Verbesserung auf. Ende 1996 mehrten sich die Anzeichen für die Rückkehr zu einem rascheren Wachstum. Nach den neuesten Daten haben sich das Wachstum der Investitionen des privaten verarbeitenden Gewerbes wie auch der Exportumsätze beschleunigt und das Geschäftsklima verbesserte sich.

Insgesamt könnte das BIP-Wachstum 1997 2,5\% betragen und 1998 auf $3,5 \%$ steigen. Die Arbeitslosenquote könnte weiter sinken und etwa $9 \%$ erreichen. Gleichzeitig werden 1997 wohl nur begrenzte Fortschritte bei der Inflationsbekämpfung erzielt (1997, 17 bis $18 \%$ ).

Dank der ausgewogeneren Finanzpolitik und der über die zentralen Tarifverhandlungsmechanismen erreichten Lohndämpfung hat sich die Lage für die monetäre Politik entspannt. Das Defizit des Sektors Staat konnte um über die Hälfte zurückgeführt werden, nämlich zwischen 1994 und 1996 von 8,4\% auf 3,1\% des BIP. Vor allem aufgrund der Privatisierungserlöse verringerte sich die Bruttoinlandsschuld, die $1994 / 95$ bei $86 \%$ des BIP gelegen hatte, 1996 auf $75 \%$ und wird 1997 voraussichtlich auf $70 \%$ sinken. Die Reaktion der Wirtschaft auf die mit der Marktöffnung verbundenen Herausforderungen war positiv, so hat sich das Handelsvolumen seit 1990 um $40 \%$ erhöht und der Anteil mit den westlichen Ländern auf über $70 \%$ verdoppelt. Einen wesentlichen Beitrag zu diesem Prozeß haben die ausländischen Direktinvestoren geleistet, sowohl im Rahmen von Privatisierungen, als auch von Unternehmensneugründungen. Ungarn ist zum Beispiel zu einem wichtigen Hersteller von Autoteilen für den europäischen Markt geworden. Industriegüter haben einen wachsenden Anteil an seiner Ausfuhr.

Einen entscheidenden Anteil der ungarischen Ausfuhr (bereits über $70 \%$ ) wird durch die mit ausländischem Kapital entstandenen gemischten Unternehmen abgewickelt.

Insgesamt gesehen haben die in den letzten zwei Jahren im Bereich der Strukturreformen erzielten Fortschritte die notwendigen Voraussetzungen geschaffen, damit Ungarn die Vorteile einer wettbewerbsoffenen, unternehmensorientierten Wirtschaft nutzen kann.

Von 1990 bis Anfang 1997 wurden etwa 40 Milliarden USD Direktkapital in der Region Mittel-Osteuropas angelegt, davon 17 Milliarden US-Dollar in Ungarn. Die wichtigsten deutschen Investoren sind Deutsche Telekom, Volkswagen-Audi, Allianz, Ruhrgas, VEW Energie, Siemens, Thyssen, Henkel, usw.

Das Bruttoinlandsprodukt wird sich in den ersten drei Monaten 1997 im Vergleich zum gleichen Zeitraum des Vorjahres um 1,2\% erhöhen. Die Bruttoproduktion der Industrie und des Baugewerbes sind noch wesentlich stärker gewachsen (um 6 bis $8 \%$ ).

Was unsere Wirtschaftsbeziehungen anbelangt, wuchs der deutsch-ungarische Handel auch im vergangenen Jahr weiter. Das Handelsvolumen zwischen Deutschland und Ungarn stieg von 7,3 Mrd. US-Dollar 1995 auf mehr als 7,6 Mrd. US-Dollar im Jahr 1996.

Die Handelsbilanz zwischen Deutschland und Ungarn war 1996 fast ausgeglichen. Ungarn exportierte 1996 Waren im Wert von 3,8 Mrd. US-Dollar nach Deutschland. Das sind $29 \%$ der gesamten ungarischen Exporte und sogar 42,5\% der ungarischen Exporte in die EU.

Ungarn importierte aus Deutschland im vergangenen Jahr Waren im Wert von etwa 3,8 Mrd. US-Dollar. Das entspricht etwa $23,5 \%$ der gesamten ungarischen Importe. Für 1997 rechnet man mit einer Steigerung der 
gesamten ungarischen Ex- und Importe um 4 bis $6 \%$. Im Handelsverkehr mit Deutschland werden die Ex- und Importe nach dieser Prognose 1997 um 6 bis $8 \%$ zunehmen. Die Daten im ersten Halbjahr 1997 unterstützen diese Vorstellungen.

Schon $34,5 \%$ des in private Betriebe investierten ausländischen Kapitals kommt aus Deutschland. Die ausländischen Investitionen konzentrieren sich auf Budapest, wohin 55,5\% des Kapitals flossen. Weiterhin bedeutend sind die Komitate Györ-Moson-Sopron und Fejér mit zusammen $22 \%$.

Die durch den AG-Assoziierungsvertrag vorgeschriebene Angleichung der ungarischen Gesetze an das Recht der EU nimmt immer deutlicher Gestalt an. Auch in diesem Jahr hat der ungarische Gesetzgeber viele Gesetze, mit denen deutsche Unternehmer in Kontakt kommen, geändert, ergänzt, neu gefaßt oder erlassen.

(Quelle: Jahresbericht der Deutsch-Ungarischen Industrie und Handelskammer, Bericht vom Ministerium für Industrie, Handel und Tourismus).

\section{Verfasser}

\section{Ferenc Takács}

Wirtschaftsattaché der Botschaft der Republik Ungarn Außenstelle Berlin

Tel. +49 (0) 30 - 2202561 